\title{
THE EFFECT OF REPRODUCTIVE HEALTH GYMNASTICS ON MENSTRUAL PAIN AMONG FEMALE ADOLESCENTS AT SOWI HEALTH CENTER, WEST PAPUA
}

\author{
Bahrah, Yuni Subhi Isnaini \\ School of Health Polytechnics, Ministry of Health \\ Sorong, Papua, Indonesia
}

\begin{abstract}
Background: Female adolescents entering puberty will experience menstruation. They are at risk of experiencing dysmenorrhea or menstrual pain. One of the non-pharmacological therapies that may be beneficial to overcome dysmenorrhea is reproductive health exercise. This exercise may increase the production of endorphin and serotonin, which have pain reducing effect. This study aimed to analyze the effect of reproductive health gymnastics on menstrual pain among female adolescents.

Subjects and Method: A randomized controlled trial was conducted at Sowi Health Center, Manokwari, West Papua. A sample of 20 female adolescents aged 12-15 years was selected at random. The dependent variable was dysmenorrhea. The independent variable was reproductive health gymnastics. The intervention was given three times a week with 15-20 minutes for one month. Dysmenorrhea was measured by visual analog scale (VAS). Pain level before and after the intervention was assessed by paired t-test.

Results: Mean of dysmenorrhea after reproductive health gymnastic (Mean=2.00; $\mathrm{SD}=$ $0.10)$ was lower than before $(M e a n=2.60 ; \mathrm{SD}=0.90)$, and it was statistically marginally significant $(\mathrm{p}=0.067)$.

Conclusion: Reproductive health gymnastics is effective in reducing dysmenorrhea in female adolescents.

Keywords: female adolescents, menstrual pain, reproductive health gymnastics

\section{Correspondence:}

Bahrah. Health Polytechnic, Ministry of Health, Sorong. Jl. Slamet Riyadi, Ambon Village, Manokwari, West Papua, Indonesia. Email: rha_poe@yahoo.co.id. Mobile: +6281248296303
\end{abstract}

